\title{
FACTORS AFFECTING LUMINESCENCE INTENSITY OF LANTHANIDE IONS. ANALYTICAL APPLICATIONS OF LANTHANIDE LUMINESCENCE IN SOLUTION
}

\author{
S. LIS \\ Department of Rare Earths, Faculty of Chemistry, Adam Mickiewicz University \\ Grunwaldzka 6, 60-780 Poznań, Poland
}

The factors which efficiently reduce nonradiative energy degradation of the lanthanide ion fluorescence are described. The most sensitive systems in spectrofluorimetric determination of trace amounts of lanthanide ions based on the complex formation, intramolecular energy transfer and mixed complexes with synergic agents in a liquid phase, are presented. Detection limits of highly sensitive systems obtained with the use of conventional and laser-excited spectrofluorimetry for $\mathrm{Sm}$ (III), $\mathrm{Eu}(\mathrm{III}), \mathrm{Tb}$ (III) and $\mathrm{Dy}$ (III) are compared.

PACS numbers: $78.55 .-\mathrm{m}$

\section{Introduction}

While the fluorescence of organic molecules has been greatly exploited in chemical (physico-chemical and biochemical) research, metal ion luminescence remains relatively undeveloped as a technique. This is due to the fact that among all of metallic cations in the periodic table only certain members of the lanthanide series (and actinides) are capable of luminescence emission in solution at room temperature.

Trivalent lanthanide ions [Ln(III)] show a characteristic line emission, called "ion fluorescence", originating within the $4 f^{n}$ configurations when optically excited. In solution fluorescence is observed only from the middle of the lanthanide series ( $\mathrm{Sm}, \mathrm{Eu}, \mathrm{Gd}, \mathrm{Tb}$ and $\mathrm{Dy}$ ) [1]. The luminescence of $\mathrm{Ln}$ (III) ions is extremely weak when compared to organic fluorophores. This weakness of luminescence arises principally from the low oscillatory strength $\left(\approx 10^{-6}\right)$ of their absorption bands which makes it difficult to achieve sufficient excited-states populations for the study of these ions in dilute systems using ordinary fluorimetry. The inherent weakness of $\operatorname{Ln}$ (III) ion luminescence is overcome by a complex formation of the lanthanide ions with appropriate ligands or an energy transfer from a ligand to the Ln(III) in 
complexes, dramatically enhancing the intensity of $\operatorname{Ln}(\mathrm{III})$ ion fluorescence [2-4], which is of particular analytical interest.

The intensity of the lanthanide ion fluorescence is mainly controlled by two important factors: first, the extent of nonradiative deactivation (quenching) of the excited state of the lanthanide ion; and second, the ability of the excited (triplet) state of the ligand to transfer energy to the emitting state of the $\operatorname{Ln}(\mathrm{III})$ ion. These factors are influenced by the nature of the ion, the ligand, the ion-ligand bond, loosely attached adduct and the solvent [2-4].

The principal quenching mechanism is the deactivation of the $\operatorname{Ln}$ (III) ion via vibronic coupling to the ligands and hence to the surrounding solvent [5]. In aqueous solution, the dominant mode of quenching of the excited $\operatorname{Ln}($ III) ion occurs via vibronic coupling of the electronic excitation to $\mathrm{O}-\mathrm{H}$ oscillators of the water molecules in the inner-coordination sphere of the ion. The replacement $\mathrm{H}_{2} \mathrm{O}$ by other ligating molecules in this coordination sphere reduces the quenching efficiency.

For the spectrofluorimetric determination of lanthanide(III) ions (i.e. Sm, $\mathrm{Eu}, \mathrm{Tb}$ and $\mathrm{Dy}$ ) their strongest fluorescence lines are analytically useful. These ion fluorescence lines, together with the corresponding $f f$ transition are listed in Table I and shown in Fig. 1. The Gd(III) does not exhibit ion fluorescence in complexes with most organic ligands, because its lowest excited (emitting) level lies far above the triplet level of the ligands.
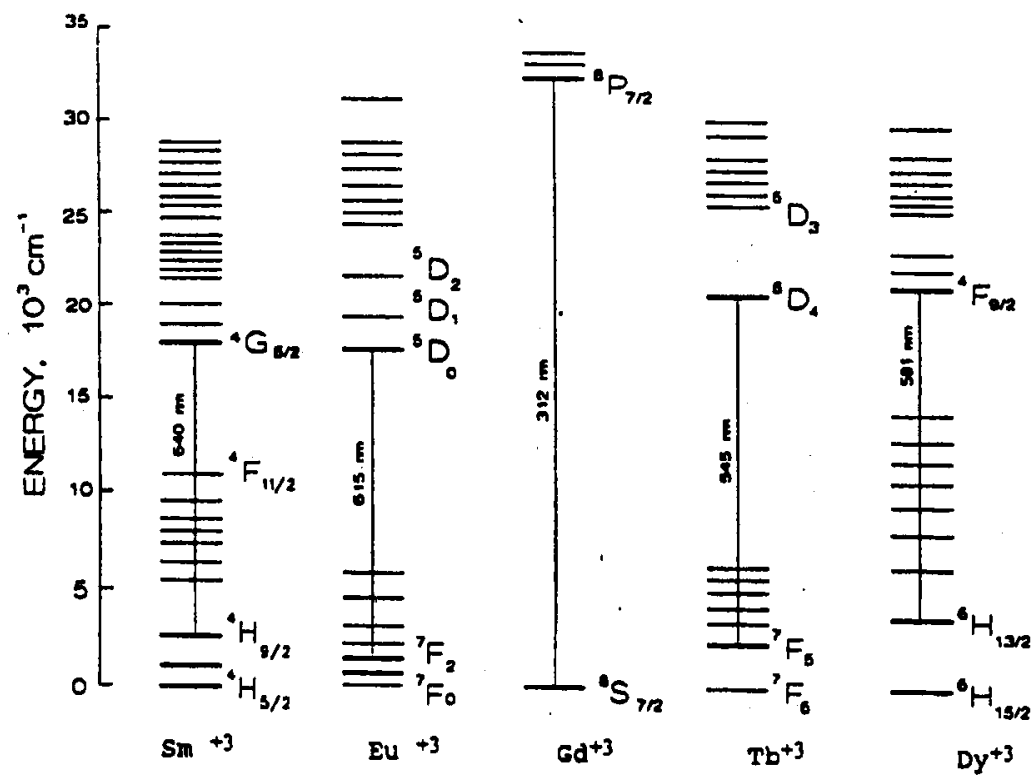

Fig. 1. Schematic diagram of energy levels and principal lines of a luminenscent lanthanide ion. 
TABLE I

The positions of the analytically useful peaks for the lanthanide together with the corresponding transitions.

\begin{tabular}{c|c|c}
\hline \hline Ion & Peak position, $\lambda_{\max }[\mathrm{nm}]$ & Transition \\
\hline $\mathrm{Sm}(\mathrm{III})$ & 640 & ${ }^{4} G_{5 / 2} \rightarrow{ }^{6} H_{9 / 2}$ \\
$\mathrm{Eu}(\mathrm{III})$ & 615 & ${ }^{5} D_{0} \rightarrow{ }^{7} F_{2}$ \\
$\mathrm{~Tb}(\mathrm{III})$ & 545 & ${ }^{5} D_{4} \rightarrow{ }^{7} F_{5}$ \\
$\mathrm{Dy}(\mathrm{III})$ & 581 & ${ }^{4} F_{9 / 2} \rightarrow{ }^{6} H_{13 / 2}$
\end{tabular}

\section{Complex formation}

Complexation of the $\operatorname{Ln}(\mathrm{III})$ results in enhancement of their luminescence as the quenching solvent molecules are removed from the first coordination sphere of the cation.

Of special analytical interest are the methods making use of the formation of stable $\operatorname{Ln}(\mathrm{III})$ complexes with aminopolycarboxylic acids which show a very intensive fluorescence in aqueous solutions [6, 7]. Ternary complexes of $\mathrm{Tb}$ (III) and $\mathrm{Dy}$ (III) with ethylenediaminetetraacetic acid (EDTA) and salicylic acid [8], and EDTA and Tiron (disodium 1,2-dihydroxybenzene-3,5-disulfonate) $[9,10]$, and complexes of $\mathrm{Tb}(\mathrm{III})$ and $\mathrm{Dy}$ (III) with iminodiacetic acid (IDA) and Tiron [11] have been also applied for analytical purposes.

In our previous investigations it has been shown that there is a possibility of using the $\mathrm{Tb}$ (III) ternary complexes with nitrilotriacetic acid (NTA) and Tiron for determination of this ion [12]. The spectrophotometric and spectrofluorimetric studies of the Ln/NTA/Tiron system proved a usefulness of this system for spectrofluorimetric determination of trace amounts of terbium [13]. The detection limit was $0.026 \mathrm{ng} \mathrm{ml}^{-1}\left(1.6 \times 10^{-10} \mathrm{~mol} \mathrm{l}^{-1}\right)$. The method enables one the determination of $\mathrm{Tb}$ (III) also in presence of a 10 -fold excess of other rare earth ions and a large excess of various metal ions and anions in the examined solutions.

\section{Intramolecular energy transfer}

The intramolecular energy transfer from the triplet state of the organic ligand to the lanthanide ion, depending on the structure of the ligand and the position of its triplet level, markedly increase the fluorescence intensity $[14,15]$. The $\beta$-diketone chelates of $\mathrm{Sm}(\mathrm{III}), \mathrm{Eu}(\mathrm{III}), \mathrm{Tb}$ (III), and $\mathrm{Dy}$ (III) showing very strong ion fluorescence, attributed to the fact of the efficient intramolecular triplet-to-emitting level energy transfer, are the most extensively studied and used in analytical applications $[16-20]$.

The use of $\beta$-diketone chelating agents, which serve as good donors for lanthanide luminescence, enables one the spectrofuorimetric analysis of trace amounts of $\operatorname{Ln}(\mathrm{III})$ ions. The thenoyltrifluroacetonate (TTA) chelates, acetylacetonates (acac), benzoylacetonates (BAC), and other $\beta$-diketone chelates in various solu- 
tions are especially bright emitters [21]. Numerous papers have been published on the topic including the recent review [22].

We have studied the possibility of applying spectrofluorimetric methods for determination of $\mathrm{Sm}$ (III), Eu(III), $\mathrm{Tb}$ (III) and $\mathrm{Dy}$ (III) using acetylacetone (acac) in ethanol solution [23]. The greatest fluorescence intensities, due to an efficient energy transfer, have been observed for the systems of $\mathrm{Tb}$ (III) and $\mathrm{Dy}$ (III), when a concentration of acetylacetone was equal to $3 \times 10^{-4} \mathrm{~mol} \mathrm{l}^{-1}$. After excitation of $\mathrm{Ln}(\mathrm{III}) /$ acac system in ethanol solution at a wavelength of $310 \mathrm{~nm}$ very intensive luminescence has been observed. We have worked out methods for determination of trace amounts of $\mathrm{Tb}$ (III) [17] and $\mathrm{Dy}$ (IIII) [18]. The dependence of $\mathrm{Tb}$ (III) fluorescence intensity $\left(\lambda_{\mathrm{em}}=545 \mathrm{~nm}\right)$ upon the $\mathrm{Tb}(\mathrm{III})$ concentration is linear for $\mathrm{Tb}$ (III) concentration in the range of 4 to $40 \mathrm{ng} \mathrm{ml}^{-1}$. The method enables one the determination of $\mathrm{Tb}(\mathrm{III})$ in the presence of a very large excess (above 100-fold) of the lanthanide(III), ittrium(III), several metal ions and anions.

For the determination of Dy(III) the strongest fluorescence band at $581 \mathrm{~nm}$ has been chosen. The luminescence intensity of Dy(III) was a linear function of concentration in the range of 0.054 to $0.482 \mu \mathrm{g} \mathrm{ml}^{-1}$. The influence of the lanthanides(III), yttrium(III) and several common metal ions and anions, present in excess in comparison with Dy(III), was examined. The presence of these ions in about 10 -fold excess was taken as the criterion for interference in this method (quenching $\approx 6.5 \%$ ).

To confirm the potential usefulness of the method based on the system with acetylacetone in ethanol solution, we modified the method for determination of small quantities of $\mathrm{Tb}(\mathrm{III})$ in pure yttrium oxide, and obtained a patent report on this subject [24]. The analytical procedure described in this report is recommended for the control of purity of ittrium oxide.

\section{Systems containing synergic agents}

The synergic agents (neutral donors) act as a shield, protecting the chelate from internal interactions and efficiently reducing nonradiative energy degradation of the lanthanide ion fluorescence.

Radiation is absorbed at a wavelength characteristic of the ligand and emitted as a characteristic line spectrum of the lanthanide ion $[5,14]$ because of the intramolecular energy transfer from the ligand to the metal ion (Fig. 2). For the intramolecular energy transfer the following requirements must be fulfilled: deactivating ligand transitions $S_{1} \rightarrow S_{0}$ and $T_{1} \rightarrow S_{0}$ should be minimal; the energy of the emitting level of the lanthanide ion should be just below that of the triplet-state of the ligand, so that the probability of transition from the triplet to emitting level $\left(T_{1} \rightarrow f f\right)$ is high, and radiationless transitions of the excited metal ion should be low.

The $\beta$-diketone chelates of $\mathrm{Sm}(\mathrm{III}), \mathrm{Eu}(\mathrm{III}), \mathrm{Tb}(\mathrm{III})$, and $\mathrm{Dy}(\mathrm{III})$ showing very strong ion fluorescence, attributed to the fact of the efficient intramolecular triplet-to-emitting level energy transfer, are the most extensively studied and used in analytical applications [16-20].

The $\beta$-diketone chelates form complexes with synergic agents. Trioctylphos- 


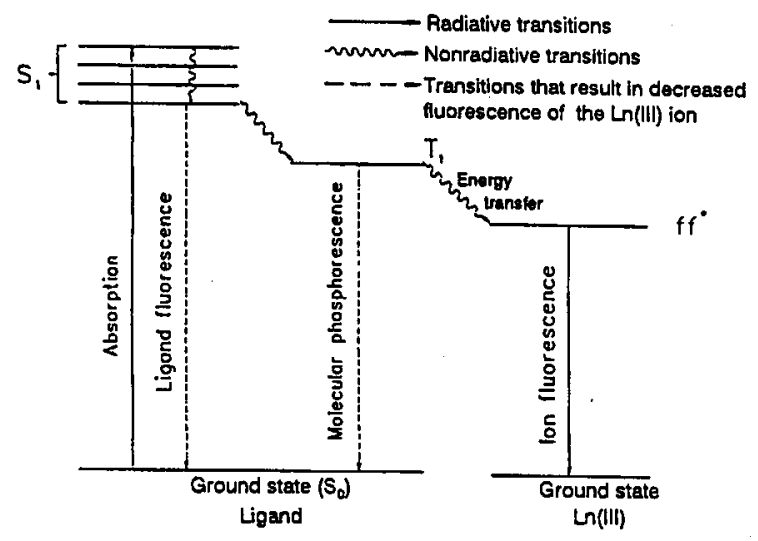

Fig. 2. Energy transfer mechanism in lanthanide(III) chelates.

phine oxide (TOPO), tributhylphosphate (TBP) and dihexylsulfoxide (DHSO) are the most effective synergic agents [25]. Ternary complexes of europium, samarium and terbium with $\beta$-diketone and a neutral donor extracted into organic solvents are useful for spectrofluorimetric determinations of these ions [26-28]. Spectrofluorimetric determination of $\mathrm{Eu}$ (III) and $\mathrm{Sm}$ (III) as their 2-naphthoyltrifluoroacetone-trioctylphosphine was described by Shigematsu et al. [26]. Fisher and Winefordner optimized experimental conditions for the fluorimetric determination of europium, samarium and terbium as their hexafluoroacetylacetone-trioctylphosphine oxide complexes in methylcyclohexane [27].

Taketatsu and Sato [28] noticed that the complexes of $\mathrm{Eu}$ or Sm(TTA) 3 .(TOPO $)_{2}$ are readily soluble in aqueous solution containing $(0.2 \%)$ polyoxyethylene isooctylphenol (Triton X-100) at $\mathrm{pH}$ 3.6. The fluorescence intensities of these mixed complexes are considerably stronger than those of the corresponding mixed complexes extracted into several organic solvents [28].

Our previous paper concerning a luminescence study of $\mathrm{Eu}(\mathrm{III})$ complexes extracted in the organic phase has shown that the complexes of $\mathrm{Eu}(\mathrm{TTA})_{3}(\mathrm{TOPO})_{2}$ and $\mathrm{Eu}(\mathrm{TTA})_{3}(\mathrm{TBP})_{2}$ are characterized by a very strong $\mathrm{Eu}(\mathrm{III})$ emission [29]. Luminescence of $\mathrm{Eu}$ (III) and $\mathrm{Sm}$ (III) in complexes with TTA and synergic agents such as TOPO, TBP or TPPO (TPPO = triphenylphosphine oxide) extracted in benzene phase have been tested in order to find a possibility of determining trace amounts of these ions. On the basis of this study a very sensitive procedure of detection of ultratrace amounts of $\mathrm{Eu}(\mathrm{III})$ in spectroscopically pure of samarium compounds, particularly oxides, has been patented [30].

Table II lists the most sensitive systems in spectrofluorimetric determinations of terbium and dysprosium and the corresponding limits of detection. 
TABLE II

Summary of several most sensitive systems and corresponding to them limits of detection (LOD) in spectrofluorimetric determination of terbium, dysprosium, europium and samarium.

\begin{tabular}{|c|c|c|c|}
\hline Complexing agents (solvent) & $\begin{array}{c}\text { LOD Tb(III) } \\
{\left[\mathrm{ng} \mathrm{ml}^{-1}\right]}\end{array}$ & $\begin{array}{c}\text { LOD Dy(III) } \\
{\left[\mu \mathrm{g} \mathrm{ml}^{-1}\right]}\end{array}$ & $\begin{array}{l}\text { Refs. } \\
\text { no. }\end{array}$ \\
\hline EDBHPA $\left(\mathrm{H}_{2} \mathrm{O}\right)$ & $\overline{1}$ & - & {$[6]$} \\
\hline$o$-HPIDA $\left(\mathrm{H}_{2} \mathrm{O}\right)$ & 0.01 & - & {$[7]$} \\
\hline EDTA-SSA $\left(\mathrm{H}_{2} \mathrm{O}\right)$ & 6 & - & [8] \\
\hline EDTA-Tiron $\left(\mathrm{H}_{2} \mathrm{O}\right)^{*}$ & 30 & 100 & {$[9,10]$} \\
\hline IDA-Tiron $\left(\mathrm{H}_{2} \mathrm{O}\right)$ & 0.004 & 0.8 & [11] \\
\hline acac (ethanol)* & 4 & 54 & {$[17,18]$} \\
\hline NTA-Tiron $\left(\mathrm{H}_{2} \mathrm{O}\right)^{*}$ & 0.026 & - & [15] \\
\hline Complexing agents (solvent) & $\begin{array}{c}\text { LOD Eu(III) } \\
{\left[\mathrm{ng} \mathrm{l}^{-1}\right]}\end{array}$ & $\begin{array}{c}\text { LOD Sm(III) } \\
{\left[\mathrm{ng} \mathrm{l}^{-1}\right]}\end{array}$ & $\begin{array}{c}\text { Refs. } \\
\text { no. }\end{array}$ \\
\hline TTA+TOPO+TX100 $\left(\mathrm{H}_{2} \mathrm{O}\right)$ & 1500 & 15000 & [28] \\
\hline $\mathrm{HFAA}+\mathrm{TOPO}+\mathrm{TX} 1000\left(\mathrm{H}_{2} \mathrm{O}\right)$ & 800 & 90000 & [28] \\
\hline TTA (ethanol) & 4 & 600 & {$[32]$} \\
\hline TTA (ethanol)** & 0.0004 & 0.08 & [32] \\
\hline TTA-TOPO (hexane) & 6 & 180 & {$[34]$} \\
\hline TTA-TOPO (hexane) ${ }^{* *}$ & 7 & 47 & [34] \\
\hline
\end{tabular}

- "Methods that enable one to determine $\mathrm{Tb}(\mathrm{III})$ and $\mathrm{Dy}(\mathrm{III})$ in the presence of a large excess of rare earth(III), various metal ions and anions.

${ }^{* *}$ These LODs were achieved with a laser-excited system.

\section{Laser-Excited spectrofluorimetry}

A lowering of the limit of detection for spectrofluorimetric determinaton of $\operatorname{Ln}$ (III) can be obtained taking advantage of using laser-excited spectrofluorimetry.

Yamada et al. [31] used highly sensitive laser fluorimetry for spectrofluorimetric determination of europium and samarium with TTA in ethanolic solution, and obtained the detection limits $4 \mathrm{ng} \mathrm{l}^{-1}$ for $\mathrm{Eu}$ (III) and $600 \mathrm{ng} \mathrm{l}^{-1}$ for Sm(III). They also obtained the lowest limit of detection using nitrogen laser excitation $(337 \mathrm{~nm})$ and a pulsed-gated photon counter [32]. The ultra-sensitive fluorescence detection was obtained for spectrofluorimetric determination of $\mathrm{Eu}$ (III) and $\mathrm{Sm}$ (III), reaching up to $0.0004 \mathrm{ng} \mathrm{l}^{-1}\left(10^{-15} \mathrm{~mol} \mathrm{l}^{-1}\right)$ for $\mathrm{Eu}$ (III) and $0.3 \mathrm{ng} \mathrm{l}^{-1}$ for $\mathrm{Sm}$ (III).

Hong et al. applied laser-induced ( $\mathrm{N}_{2}$-laser) fluorescence for determination of trace amounts of uranium, europium and samarium [33]. The measurements for $\mathrm{Eu}(\mathrm{III})$ and $\mathrm{Sm}$ (III) were performed by adding fluorescence enhancing reagent (DMSO) in methylcyclohexane. The detections limits for $\mathrm{Eu}(\mathrm{III})$ and Sm(III) were established as 0.1 and $10 \mathrm{ng} / \mathrm{ml}$, respectively. 
Anzano et al. using the conventional and laser-excited luminescence spectrometry for detection of europium and samarium studied thenoyltrifluoroacetone-trioctylphosphine oxide-Eu(III) and Sm(III) complexes in hexane. The limits of detection were $6.0 \mathrm{ng} \mathrm{l}^{-1}$ for $\mathrm{Eu}(\mathrm{III})$ and $180 \mathrm{ng} \mathrm{l}^{-1}$ for $\mathrm{Sm}$ (III) with the conventional fluorescence, and with laser-excited fluorescence (using a $325 \mathrm{~nm}$ He-Cd-laser) were $7.0 \mathrm{ng} \mathrm{l}^{-1}$ and $47 \mathrm{ng} \mathrm{l}^{-1}$, respectively.

Table II presents the most sensitive systems and corresponding to them detection limits obtained in the spectrofluorimetric determination of europium and samarium.

\section{References}

[1] S.P. Sinha in: Systematics and the Properties of the Lanthanides, Ed. S.P. Sinha, Reidel, Dordrecht 1983, p. 451.

[2] J.-C.G. Bünzli, in: Lanthanide Probes in Life, Chemical and Earths Sciences, Eds. J.-C.G. Bünzli, G.R. Choppin, Elsevier, Amsterdam 1989, Chap. 7.

[3] W.T. Carnall, in: Handbook on the Physics and Chemistry of Rare Earths, Eds. K.A. Gschneidner, L.R. Eyring, Vol. 3, North-Holland, Amsterdam 1979, Chap. 24.

[4] E. Soini, T. Lövgren, CRC Crit. Anal. Chem. 18, 105 (1987).

[5] R.E. Whan, G.A. Crosby, J. Mol. Lumin. 8, 315 (1962).

[6] T. Taketatsu, S. Yoshida, Bull. Chem. Soc. Jpn. 45, 2921 (1972).

[7] M.A. Tishchenko, N.S. Poluektov, G.F. Yaroshenko, R.P. Lastovskii, G.L. Gerasimenko, I.L. Zheltvai, L.M. Timakova, Zh. Anal. Khim. 33, 2368 (1978).

[8] R.N. Dagnall, R.S. Smith, T.S. West, Analyst 92, 358 (1967).

[9] S.J. Lyle, N.A. Za'tar, Anal. Chim. Acta 162, 305 (1984).

[10] S.J. Lyle, N.A. Za'tar, Anal. Chim. Acta 162, 447 (1984).

[11] M.A. Tishchenko, G.L. Gerasimenko, N.S. Poluektov, Zavod. Lab. 40, 935 (1974).

[12] M. Elbanowski, Z. Hnatejko, B. Mąkowska, S. Lis, Eur. J. Solid State Inorg. Chem. 28, 287 (1991).

[13] S. Lis, Z. Hnatejko, M. Elbanowski, Chem. Anal., in press.

[14] G.E. Buono-Core, H. Li, B. Marciniak, Coord. Chem. Revs. 99, 55 (1990).

[15] M.L. Bhaumik, M.A. El-Sayed, J. Chem. Phys. 42, 787 (1965).

[16] M.A. Tishchenko, I.L. Zheltvai, N.S. Poluektov, I.V. Bakshun, Zavod. Lab. 39, 671 (1973).

[17] M. Elbanowski, S. Lis, Fresenius Z. Anal. Chem. 330, 698 (1988).

[18] M. Elbanowski, S. Lis, Fresenius Z. Anal. Chem. 332, 63 (1988).

[19] Y. Jinghe, R. Xuezhen, Z. Huabin, S. Ruiping, Analyst 115, 1505 (1990).

[20] Z.M. Topilova, N.V. Rusakova, S.B. Meshkova, M.O. Lozinskii, L.S. Kudryavtseva, L.I. Kononenko, Zh. Anal. Khim. 46, 863 (1991).

[21] R. Belcher, R. Perry, W.I. Stephen, Analyst 94, 26 (1969).

[22] E.P. Diamandis, T.K. Christopoulos, Anal. Chem. 62, 1149A (1990).

[23] M. Elbanowski, S. Lis, B. Mąkowska, B. Marciniak, in: Proc. Intern. Conf. on Molecular Spectroscopy and Photophysics, Torun 1986, p. 93.

[24] S. Lis, M. Elbanowski, Patent Report P-296999 (1992). 
[25] F. Halverson, J.S. Brinen, J.R. Leto, J. Chem. Phys. 41, 2752 (1964).

[26] T. Shigematsu, M. Matsui, R. Wake, Anal. Chim. Acta 46, 101 (1969).

[27] R.P. Fisher, J.D. Winefordner, Anal. Chem. 43, 454 (1972).

[28] T. Taketatsu, A. Sato, Anal. Chim. Acta 108, 429 (1979).

[29] S. Lis, J.N. Mathur, G.R. Choppin, Solv. Extr. Ion Exch. 9(4), 637 (1991).

[30] S. Lis, Patent Report P-298021 (1993).

[31] S. Yamada, F. Miyoshi, K. Kano, T. Ogawa, Anal. Chim. Acta 127, 195 (1981).

[32] S. Yamada, K. Kano, T. Ogawa, Anal. Chim. Acta 134, 21 (1982).

[33] K.B. Hong, K.W. Jung, K.-H. Jung, Talanta 36, 1095 (1989).

[34] J.M. Anzano, A. Akseli, S.J. Lohotay, J.D. Winefordner, Anal. Lett. 24, 151 (1992). 